UNDERGROUND MINING ENGINEERING 32 (2018) 15-31 $\quad$ UDK 62

\title{
ROCK FRACTURING MECHANISMS BY BLASTING
}

\author{
Slavko Torbica ${ }^{1}$, Veljko Lapčević ${ }^{1}$
}

Received: April 3, 2018

Accepted: June 12, 2018

\begin{abstract}
Optimizing blast fragmentation and reducing the damage from it are two important research subjects in this field. Detonation and explosive charge induces three sets of tension cracks in the monolith rock. Radial tension cracks are formed under the influence of the pressure wave whose cylindrical propagation induces tension. Along with the explanation of how radial cracks are formed, formulation is given as to how their length can be calculated using laboratory and drill and blast parameters. Cracks subparallel with the free surface (face) are related with amounts of absorbed and recoverable strain energies. The distance between subsequent cracks can be calculated using the results of simple load-unload laboratory tests. Third sets of tension cracks are formed as a result of excessive deformation of the beam or cantilever formed by radial cracks. Once the length of the cracks and the distance between them are known, it is possible to apply these results for estimation of fragment sizes and blasting pattern design.
\end{abstract}

Keywords: blasting; fragmentation; rock; fracturing;

\section{INTRODUCTION}

Blasting is the dominant way of excavation in mining and tunneling and as such has been the subject of research for a long time. The blasting procedure is relatively simple, drilled holes are filled with explosive that is detonated. Detonation and gaseous products induce pressure in the rock and its fragmentation. Blasting pattern design is a process that includes selection of the proper explosive, displacement of boreholes and sequence of initiation. Holes have to be placed at a proper distance from the free surface so that there is enough energy to fracture the rock between the blasthole and free surface.

In hard rock tunneling, the main problem that occurs from blasting is the damage done to the surrounding rock mass. Detonation of explosive induces tension cracks in the rock and depending on the quality of the blasting pattern, these cracks are more or less long and may have an impact on stability and support load. Many researchers have been investigating this problem and nowadays there are a number of reports and models available (Kwon, et al., 2009; Torbica and Lapčević, 2016; Ouchterlony, et al., 2002; Hustrulid and $\mathrm{Lu}, 2002)$.

\footnotetext{
${ }^{1}$ University of Belgrade - Faculty of Mining and Geolgy
} Emails: torbica@rgf.bg.ac.rs; veljko.lapcevic@ rgf.bg.ac.rs 
The size of the rock fragments after blasting is an important parameter in mining and its determination is crucial for good production. Fragment size depends on primary jointing of the rock mass and blasting pattern. Fragmenting of the monolith rock is done through the creation of the tension cracks that form a single fragment. Most of models for fragment size estimation are based on empirical relationships coupled with statistical methods (Gheibie, et al., 2009; Ouchterlony, 2005; Cunningham, 1983). There is a lack of models based on constitutive equations able to estimate the length and spacing between blast-induced fractures in rock material.

On the other hand, there are numerous practical tests in different scales conducted. Esen et al. (2003) conducted a large number of small scale tests relating the properties of rock and explosives with the crack zone size. Olsson and Bergquist (1996) performed a series of blast tests identifying the influence of different parameters on radial cracks lengths. Ouchterlony (1997) used a curve fitting technique with in-situ data from the Vanga quarry in southern Sweden in order to obtain the relationship between explosive properties and crack lengths.

Numerical modeling of crack initiation and development is a common practice these days (Hu, et al., 2015; Goodarzi, et al., 2015; Saharan and Mitri, 2008; Zhu, et al., 2007). Numerical models can provide good insight into rock fracturing and give a good estimate of the length of blast-induced cracks or cracks induced by fracking. Also numerical models can be used for fragmentation assessment (Yi, et al., 2017), but with few limitations regarding time and cost of computation.

Herein, focus is given on explaining how tension cracks are formed under detonation of an explosive charge, with relation to how length and distance between different sets can be calculated using rock strength and deformability parameters determined in the laboratory. Possibilities for further application of the results for blasting pattern and fragmentation estimate are discussed.

\section{ROCK FRACTURING UNDER EXPLOSIVE LOAD}

\subsection{Radial tension cracks}

If we take a look at the curve of ideal and non-ideal detonation in the p-t (pressure - time) diagram (Figure 1), it can be concluded that pressure at the borehole wall is applied instantly, and then it lasts for a certain period of time. These are all properties of the impact load. This load induces a pressure wave that propagates cylindrically around the cylindrical explosive charge (Figure 2). An impact load is applied at the borehole wall in the zone of the reaction which is followed by its retention for a certain period of time. 


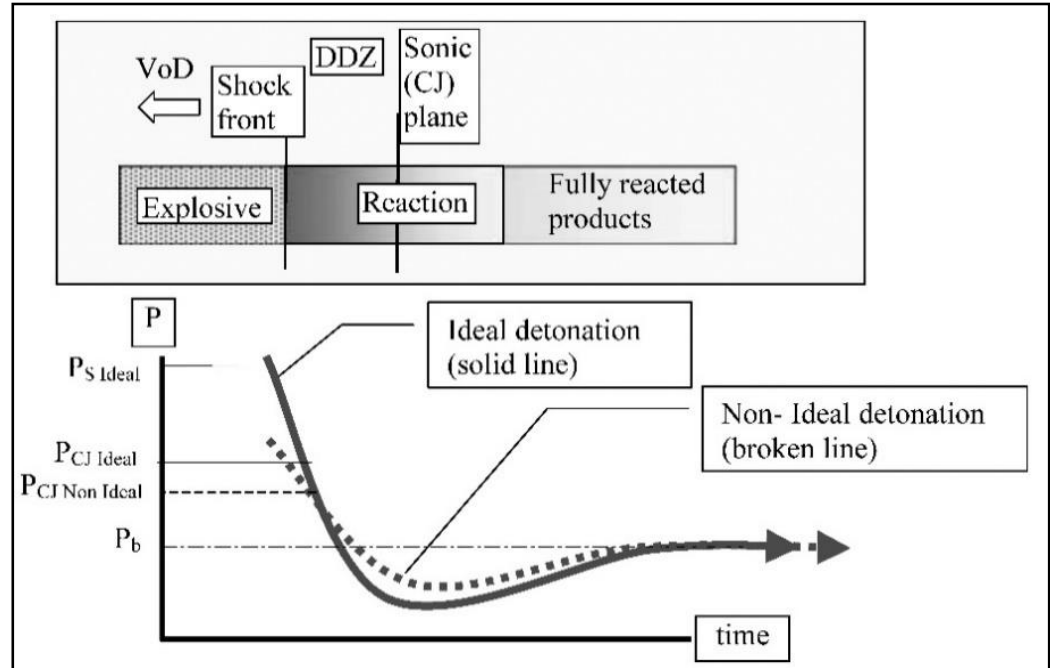

Figure 1 p-t diagram for ideal and non-ideal detonation (Cunningham, 2006)

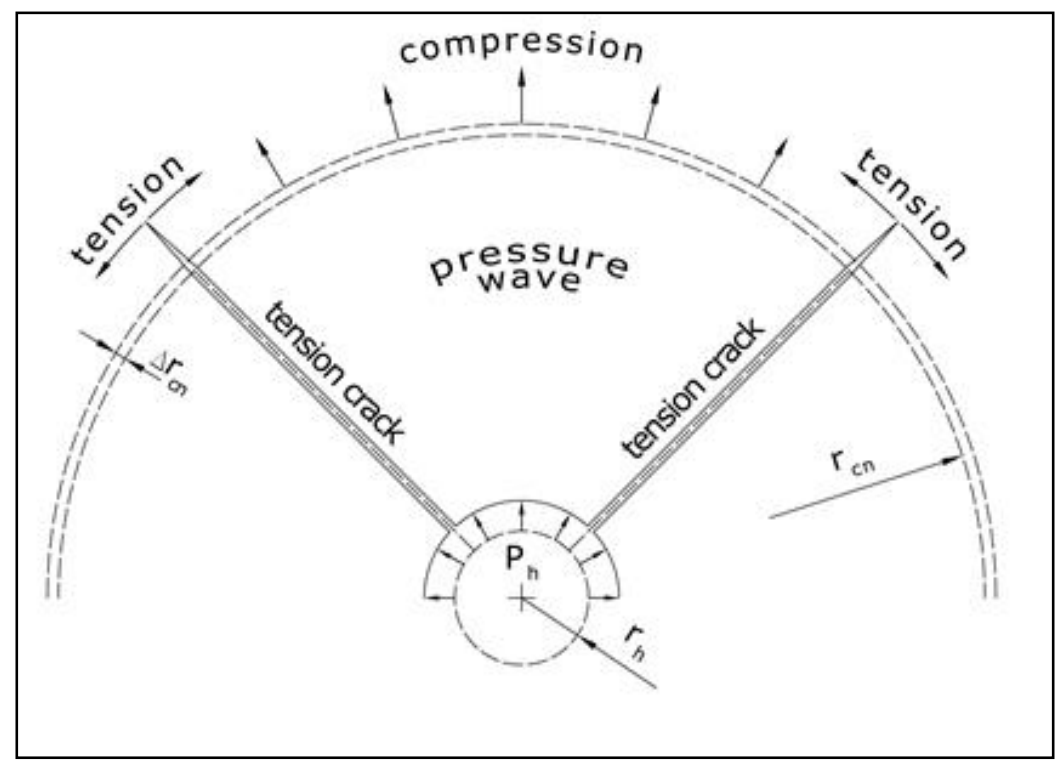

Figure 2 Schematic illustration of radial tension fractures formation 
At the distance $r_{c n}$ from the borehole compressive stress of the rock in the radial direction is (Torbica and Lapcevic, 2014):

$$
\sigma_{r c}=P_{h} \frac{r_{h}}{r_{c n}}
$$

Where:

$\sigma_{r c}$ - radial compressive stress,

$P_{h}$ - borehole pressure,

$r_{h}$ - borehole radius,

$r_{c n}$ - crack zone radius.

On the other hand:

$$
\begin{gathered}
\sigma_{r c}=M \cdot e_{r} \\
M=E \cdot \frac{(1-v)}{(1+v)(1-2 v)}
\end{gathered}
$$

Where:

$M$ - pressure wave modulus (Mavko, et al., 2009)

$e_{r}$ - radial strain

$E$ - Young`s modulus of rock

$v$ - Poisson's ratio

With expression:

$$
k=\frac{(1-v)}{(1+v)(1-2 v)}
$$

Radial compressive stress from Equation (2) can be expressed as:

$$
\sigma_{r C}=E \cdot k \cdot e_{r}
$$


Then, the radial strain is:

$$
e_{r}=\frac{\sigma_{r c}}{k \cdot E}
$$

Considering Equation (1), it becomes:

$$
e_{r}=\frac{P_{h} \cdot r_{h}}{E \cdot k \cdot r_{c n}}
$$

If we focus on rock particles on the cylindrical surface at a distance $r_{\mathrm{cn}}$ from the borehole, their perimeter before the pressure wave reaches them is:

$$
O_{r_{c n}}=2 \pi r_{c n}
$$

After the pressure wave reaches these particles, they are moved to a new positions in similar cylindrical form with radius $\left(r_{c n}+\Delta r_{c n}\right)$. In this case, the perimeter is increased:

$$
O_{\left(r_{c n}+\Delta r_{c n}\right)}=2 \pi\left(r_{c n}+\Delta r_{c n}\right)
$$

Respectively:

$$
O_{\left(r_{c n}+\Delta r_{c n}\right)}=2 \pi\left(r_{c n}+e_{r} r_{c n}\right)
$$

Therefore, in front of pressure wave (in direction of its propagation), the rock is under a compressive load, and under a tensile load in perpendicular direction with the strain:

$$
e_{l}=\frac{O_{\left(r_{c n}+\Delta r_{c n}\right)}-O_{r_{c n}}}{O_{r_{c n}}}=e_{r}
$$

Respectively:

$$
e_{l}=\frac{P_{h} \cdot r_{h}}{E \cdot k \cdot r_{c n}}
$$


Strain that will form one radial tension crack at distance $r_{c n}$ is:

$$
e_{t}=\frac{\sigma_{t}}{E}
$$

Where:

$e_{t}$ - tensile strain,

$\sigma_{t}$ - tensile strength,

$E$ - Young's modulus of rock.

Number of radial tension cracks at the distance $r_{c n}$ is:

$$
n=\frac{e_{I}}{e_{t}}
$$

Respectively:

$$
n=\frac{P_{h} \cdot r_{h}}{k \cdot \sigma_{t} \cdot r_{c n}}
$$

Therefore:

$$
r_{c n}=\frac{P_{h} \cdot r_{h}}{k \cdot \sigma_{t} \cdot n}
$$

For a blasthole with radius $r_{h}=0.051 \mathrm{~m}$ and pressure in granite with tensile strength of $\sigma_{t}=14 \mathrm{MPa}$ and Poisson's ratio $v=0.25$, the cracking zones are as presented in Figure 3. 


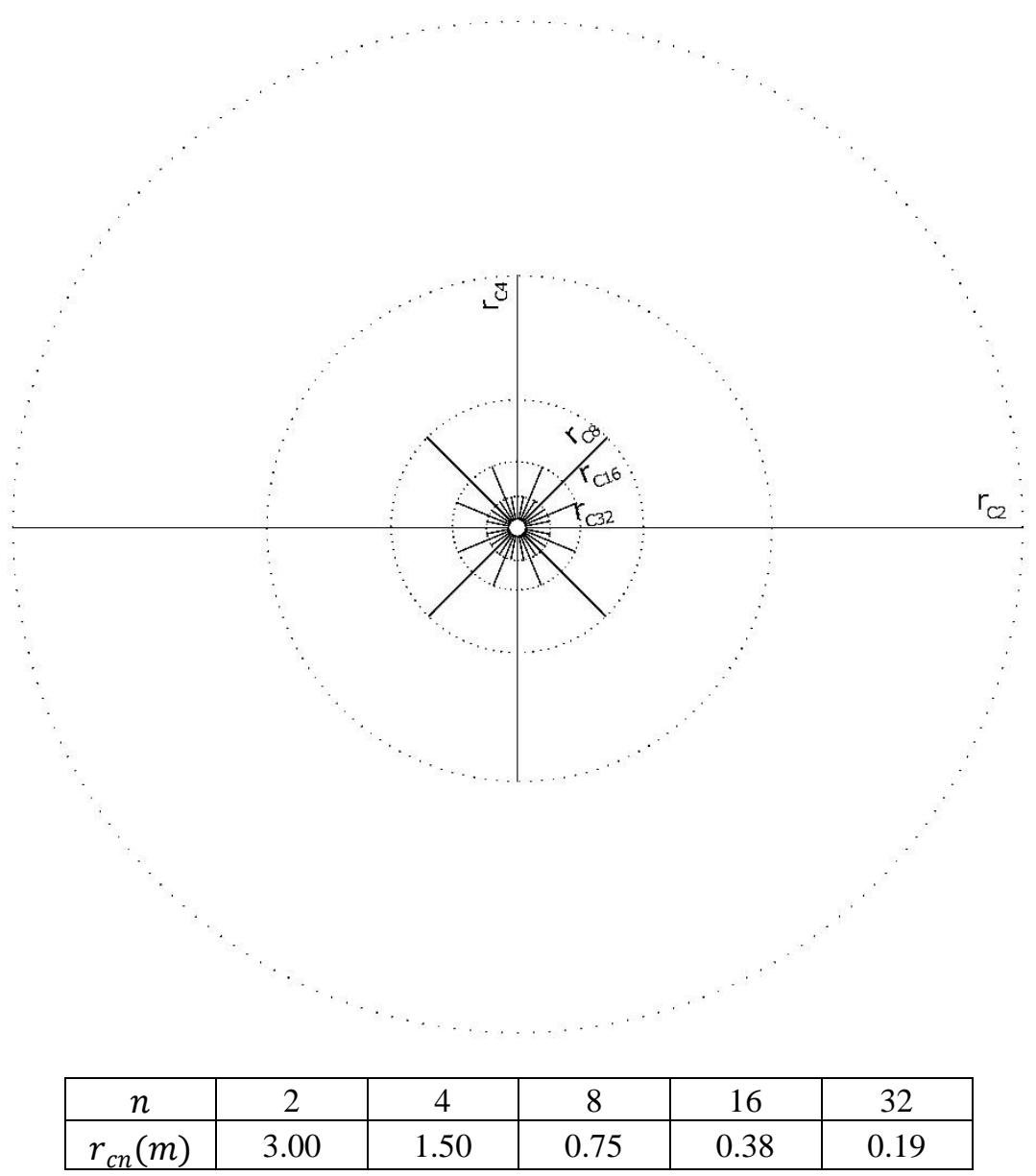

Figure 3 Illustration of tension crack length and density around the blasthole

\subsection{Tension cracks subparallel to the free surface}

As it was already mentioned, the strain in direction of the pressure wave propagation (compression) is numerically equal to the strain in the plane of the wave front (tension). Looking from the borehole, it is possible to differentiate 3 zones:

1. First zone where pressure load is larger than the rock strength and where the rock between the radial cracks is sheared. Many authors identify this zone as the crushing zone (Whittaker, et al., 1992),

2. Zone where only radial tension cracks are formed due to the plane's tension from the pressure wave front and compression in a direction perpendicular to 
the pressure wave front in the elastic zone. This is zone where only tensile failure occurs.

3. In third zone, all strains are smaller than the strain that cause rock failure. This is a zone of elastic deformations.

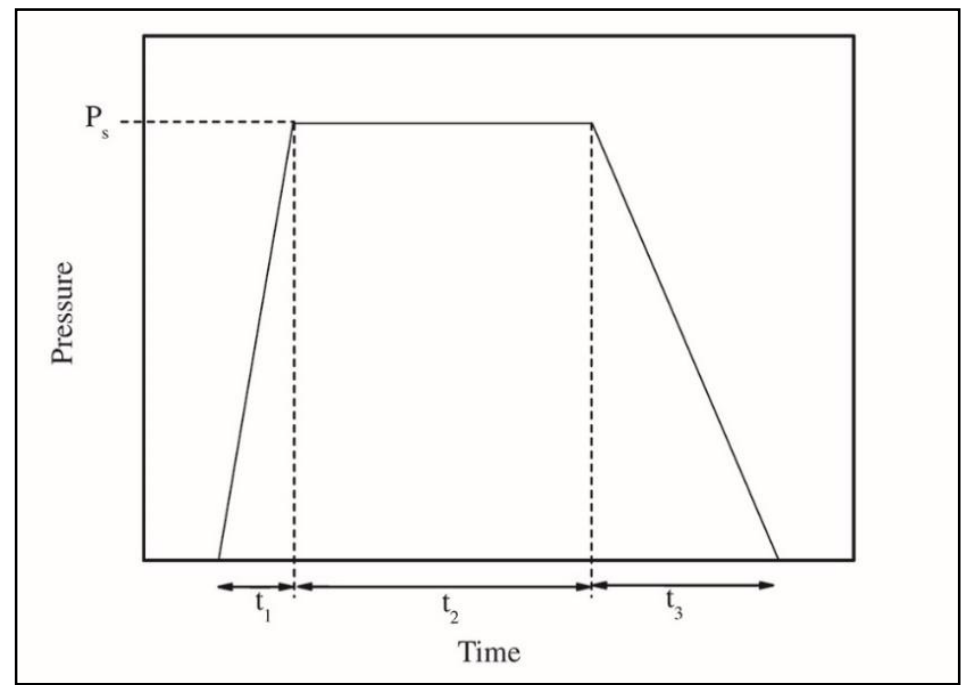

Figure 4 Pressure-time history for gas pressure in the boreholes (Cho and Kaneko, 2004)

After the drop of pressure in the blasthole, after few milliseconds, in Figure 4, the rock between the pressure wave front and crushing zone, that has been under elastic deformation, is returned to its initial deformation state.

Cylindrical explosive charge, whose axis is parallel with the free surface, placed at the distance "B" from the free surface (Figure 5) is the charge with normal burden. Distance $B$ is the burden of the explosive charge and can be calculated using the expression:

$$
B=r_{c 4} \cdot \cos 45^{\circ}
$$

Or:

$$
B=\frac{0.17 \cdot P_{h} \cdot r_{h}}{k \cdot \sigma_{t}}
$$




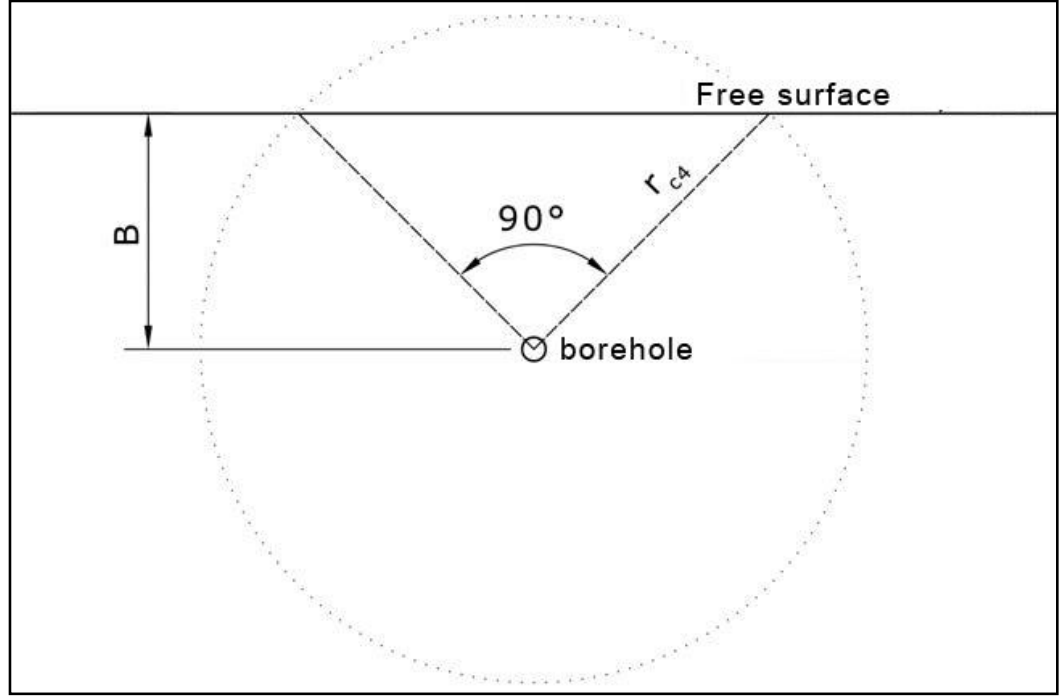

Figure 5 Normal burden of explosive charge

With the cylindrical explosive charge, with normal burden, pressure wave propagates cylindrically and forms radial tension cracks. When two radial cracks reach the free surface rock wedge is formed (Figure 6).

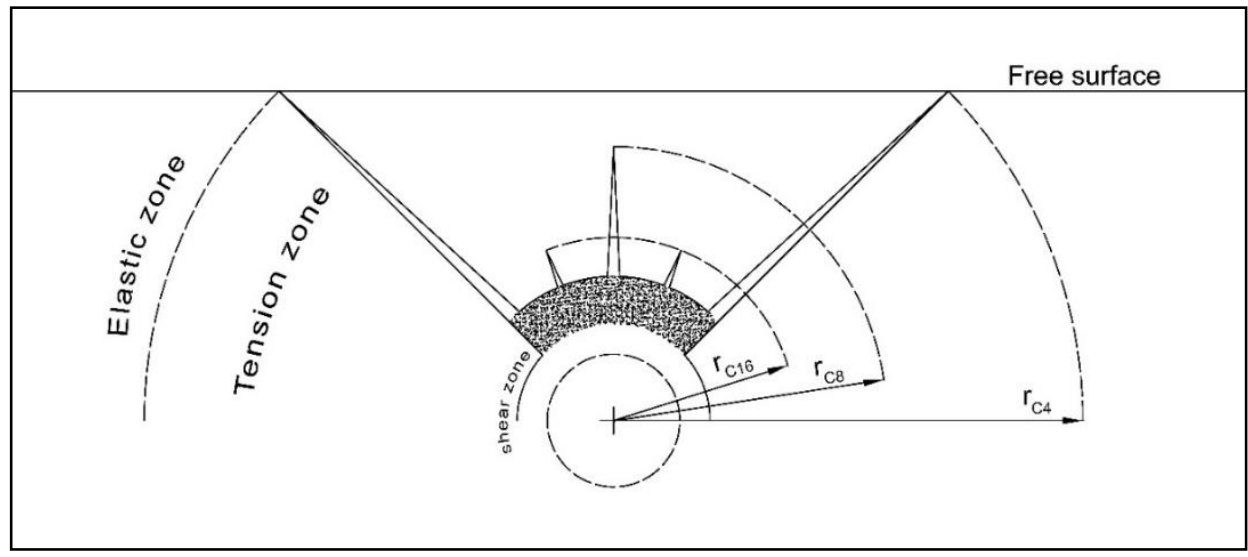

Figure 6 Rock wedge formation from two radial tension cracks

A pressure wave reaches the free surface before the wedge is formed as illustrated at Figure 7. Rock particles that form the free surface have no rock medium to transfer the strain energy, so they continue to move in same direction (pressure wave propagation). 
Next rows of particles follow this motion in same manner. The distance between the rock particles was decreased proportionally to the compressive load, i.e. intensity of pressure wave. If the rock material would be ideally elastic, rock particles would move to the equilibrium state and then continued to move for the quantity of compressive strain. This means that between two particles, tension is formed instead of compression. Strain would be same, but with a different sign.

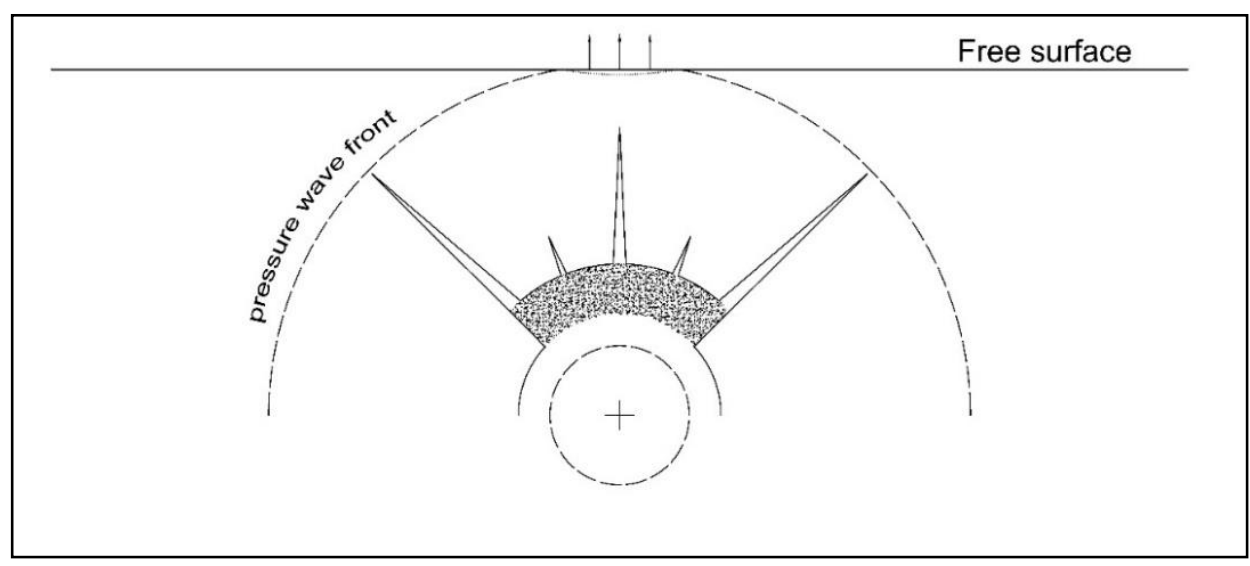

Figure 7 Pressure wave reaching the free surface

Since real rock material is not ideally elastic, but plastic, only one portion of compressive energy will be recoverable and available for tension after sudden unloading (Figure 8).

Figure 9 illustrates the complete stress-strain (loading-unloading) curves for fine grained magmatic and porous sedimentary rocks. From here, it is easy to notice the large difference between absorbed and recoverable strain energies for those typical rock materials. It is logical to conclude that ratio between compressive strain and tensile strain is the same as the ratio between total strain energy (absorbed + recoverable) and recoverable strain energy. 


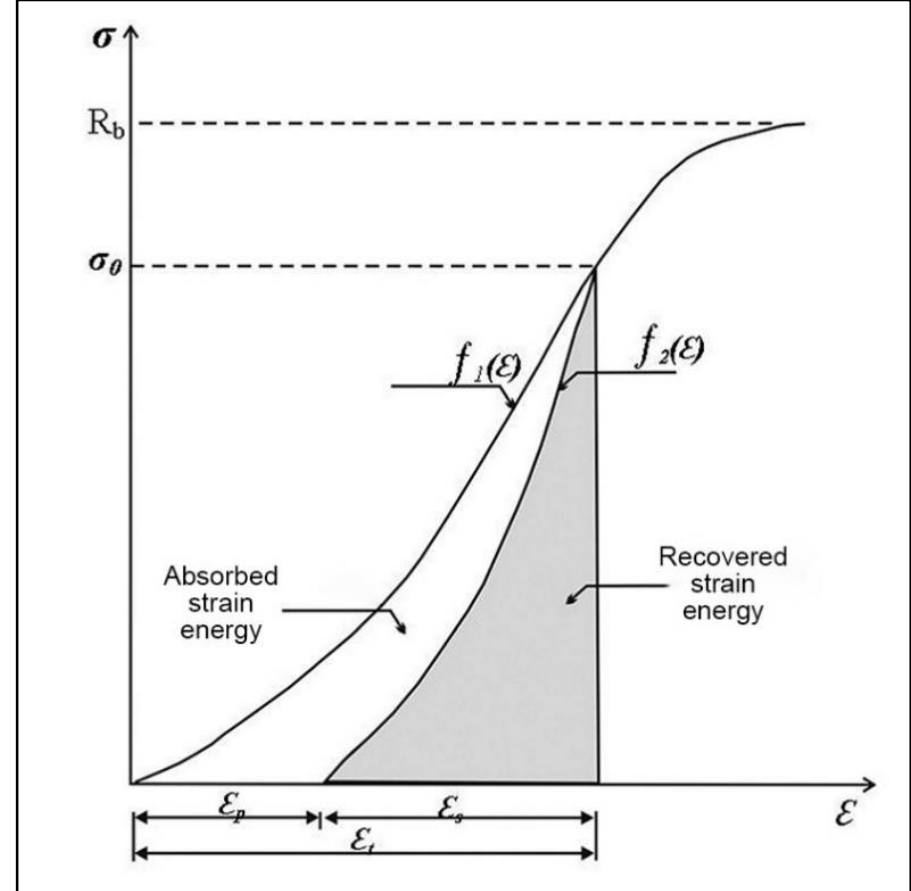

Figure 8 Absorbed and recovered strain energy

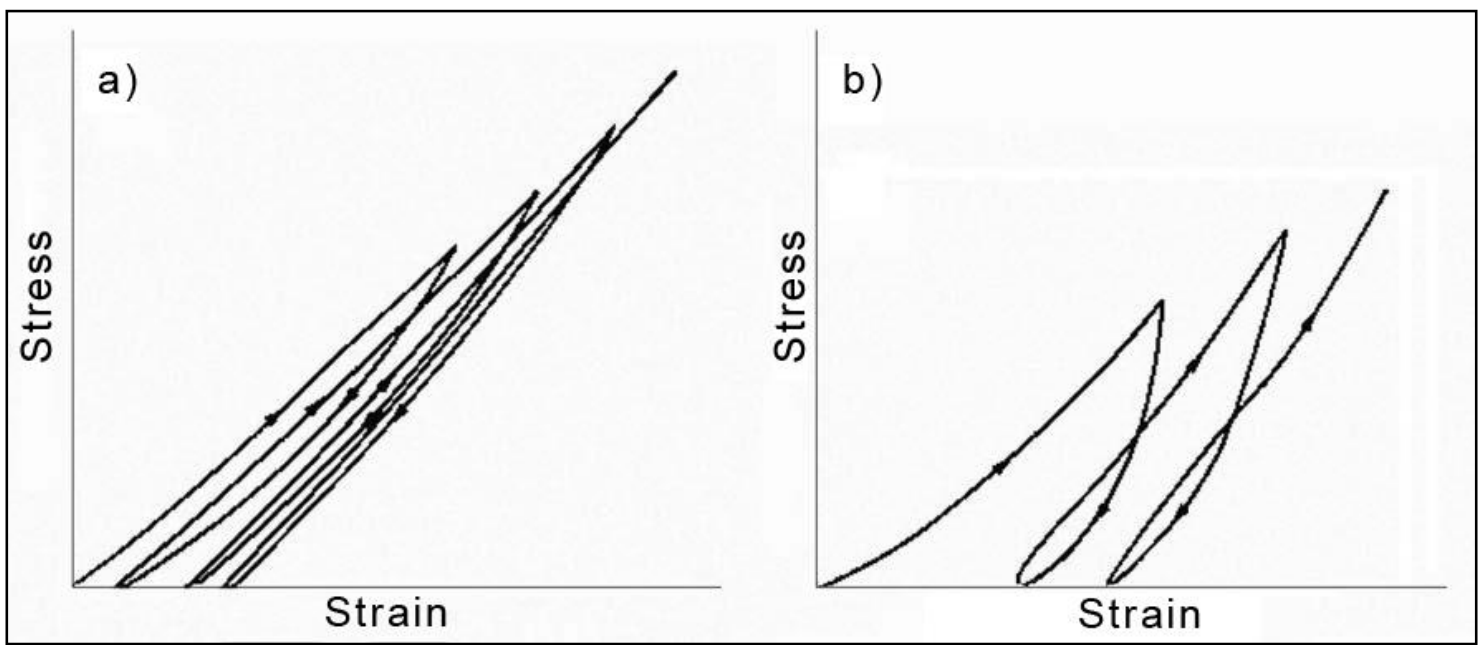

Figure 9 Complete stress-strain curves for a) fine grained magmatic rocks b) porous sedimentary rocks 
Index of strain energy recoverability (Figure 8) can be expressed as:

$$
\begin{aligned}
& I_{s r}=\frac{E_{r}}{E_{t_{t}}} \\
& E_{r}=\int_{e_{t}}^{t_{t}} f_{1}(e) d e \\
& E_{t}=\int_{0}^{e_{t}^{p}} f_{2}(e) d e
\end{aligned}
$$

Where:

$I_{s r}$ - Index of strain energy recoverability,

$E_{r}$ - recoverable strain energy,

$E_{t}$ - total strain energy (recoverable + absorbed).

Tensile strain in radial direction, at distance $B$ from the borehole, is expressed as:

$$
e_{r t}=\frac{P_{h} \cdot r_{h} \cdot I_{s r}}{k \cdot E \cdot B}
$$

For the formation of one tensile crack necessary strain is:

$$
e_{t}=\frac{\sigma_{t}}{E}
$$

At the distance $B$ number of formed tensile cracks is:

$$
n=\frac{e_{r t}}{e_{t}}=\frac{P_{h} \cdot r_{h} \cdot I_{s r}}{k \cdot B \cdot \sigma_{t}}
$$

Therefore, first tension crack subparallel with the free surface is formed at the distance $b$ from the free surface:

$$
b=\frac{B}{n}=\frac{B^{2} \cdot k \cdot \sigma_{t}}{P_{h} \cdot r_{h} \cdot I_{s r}}
$$




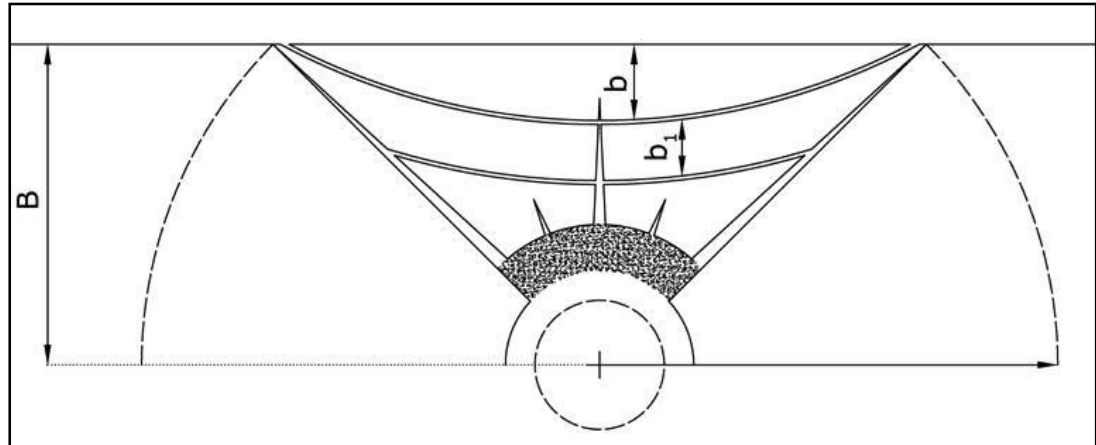

Figure 10 Formation of tension cracks subparallel with the free surface

Next, a tension crack forms at the distance $b_{1}$ that is smaller than distance $b$, since the tensile strain is larger, so distance $b_{2}$ is smaller than $b_{1}$ and so on (Figure 10).

If the explosive charge is placed at the distance:

$$
B+b<r_{4}
$$

spalling would occur, since the explosive charge is further than $B$, the radial cracks are not reaching the free surface, and the rock wedge is not separated. Anyhow, if the rock has a large recoverable strain energy, then $b$ is very small and that part of the rock is fractured, as has been already explained (Figure 11).

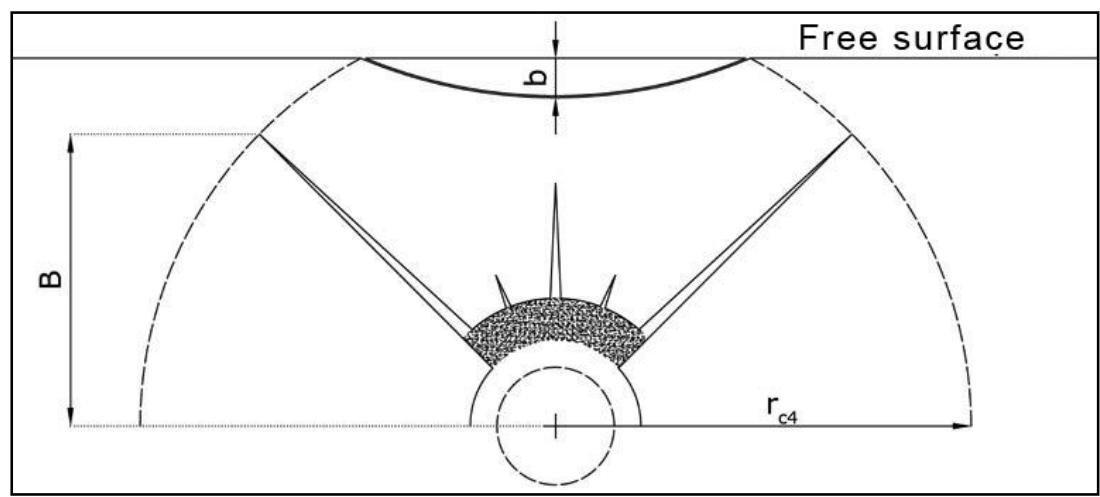

Figure 11 Spalling of free surface 


\subsection{Tension cracks perpendicular to the free surface}

Detonation is a process that lasts for a certain amount of time and propagates along the explosive charge. The explosive is placed in the borehole and the charge has a cylindrical shape (length is much large than diameter). The explosive charge is usually initiated at one end. Figure 12 illustrates the initiation of the explosive charge from the beginning of the blasthole. First, radial tension cracks are formed and if the explosive charge is at a proper distance from the free surface rock, a wedge is separated (Figure 6). Secondly, tension cracks subparallel to the free surface are formed (Figure 10). Separation of the wedge goes from the beginning to the end of the borehole and it has the form of the cantilever. Explosion gases are bending this cantilever and in the tension zone, tensile cracks are formed that are perpendicular to the free surface.

Figure 13 illustrates the initiation of the explosive charge from the bottom of the blasthole. In this case, the formation of the radial and subparallel tension cracks goes from the bottom of the blasthole. Wedge has the form of the beam fixed at both ends. When the length of the beam exceeds the critical point, bending occurs and tension cracks perpendicular to the free surface are formed in the tension one.

Radial and cracks subparallel to the free surface are formed by the pressure wave, while tension cracks that occur from the bending of beam/cantilever are caused by the pressure of the gases. Expansion of gases produces the further collision between fragments and their further fragmentation.

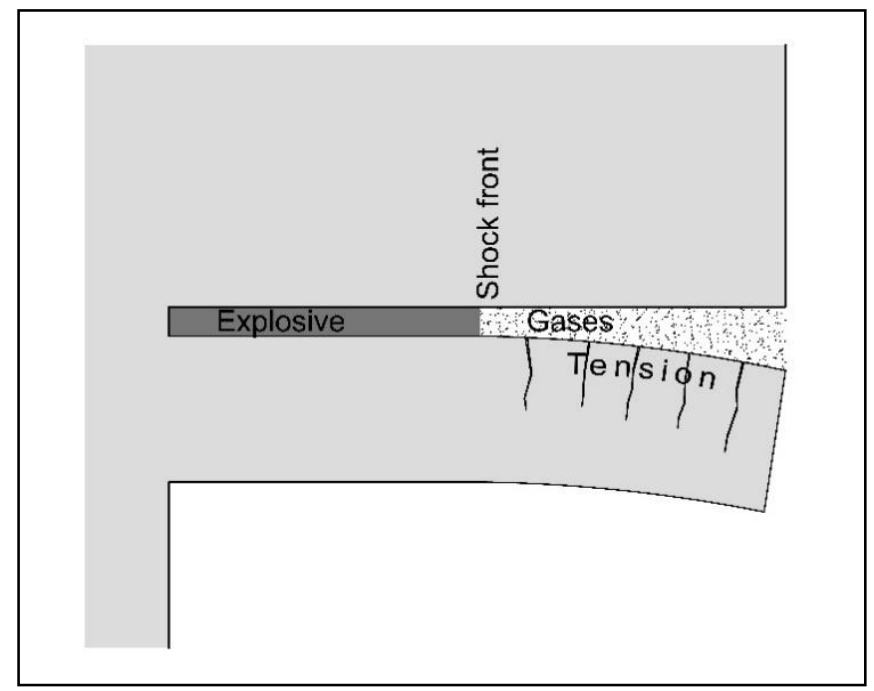

Figure 12 Explosive charge initiation from the beginning of the blasthole 


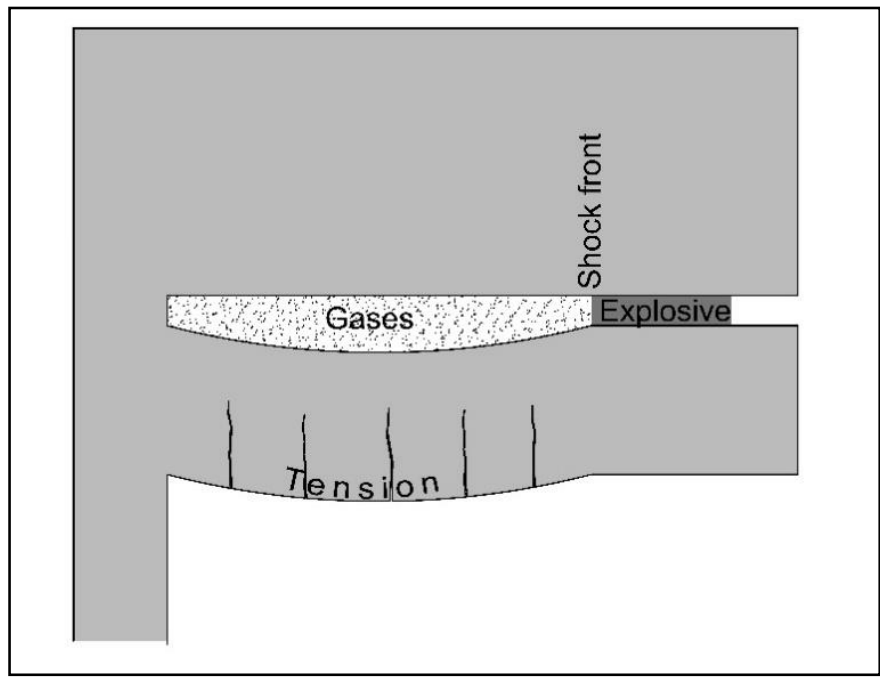

Figure 13 Explosive charge initiation from the end of the blasthole

\section{CONCLUSION}

Rock blasting has been used for long time in hard rock excavation, so many practical and theoretical techniques have been developed since then. Rock breakage under explosive load has been one of the subjects that many researchers have been focusing on. As a result, it is known that explosive detonation induces the tension cracks in the rock and its fragmentation, while gaseous products are of secondary order. Creating the proper blasting pattern assumes the proper determination of the burden of each explosive charge, and for this purpose mainly empirical or semi-empirical solutions exist.

Herein, the mechanism of monolith rock fragmentation is explained. Detonation of an explosive charge induces 3 main sets of fractures that are conditionally mutually perpendicular. If we disregard the close perimeter of blast hole where shear failure occurs, the main failure mode in the rock is by tension. Radial tension cracks are formed by the influence of the pressure wave generated by detonation. Due to its cylindrical propagation and high power, certain parts of the rock are under tension and tensile failure occurs with the remaining tension crack. In close perimeter of the blast hole, the density of these radial tension cracks is higher and decreases with the distance from the blast hole. Formulation is provided to estimate the radial crack lengths which is further used for the proper determination of the burden for an explosive charge.

The second set of tension cracks that is formed by detonation is subparallel with the free surface. Once the pressure wave reaches the free surface, particles of rock have high energy with no other rock particles to transmit it to. These particles are continuing to 
move in the direction of the stress wave propagation and at a certain distance from the free surface, a tension crack is formed and the fragment is separated from the main rock. The relationship that is provided to describe distance with subsequently formed subparallel cracks is based on the amounts of absorbed and recoverable energy that can be obtained from laboratory tests. In special conditions, when the distance between borehole and free surface is not small enough to cause rock fragmentation, the spalling effect occurs.

A third set of tension cracks is formed as a result of the excessive load of the beam or cantilever, depending on the side of the explosive initiation. All three sets form the rock fragments whose size depends on the distance between the different sets. Using the formulation provided, it is possible to apply these directly for the blasting pattern design, as well as fragment size estimation.

\section{REFERENCES}

CHO, S. H. andKANEKO, K. (2004) Rock fragmentation control in blasting. Materials transactions, 45, pp.1722-1730.

CUNNINGHAM, C. (1983) The Kuz-Ram Model for production of fragmentation from blasting. In: Proc. 1st Symp. on Rock Fragmentation by Blasting, Lulea. Lulea.

CUNNINGHAM, C. (2006) Blasthole Pressure: What it really means and how we should use it. In: Proceedings of the annual conference on explosives and blasting technique, 32, pp. 255.

ESEN, S., ONEDERRA, I. and BILGIN, H. A. (2003) Modelling the size of the crushed zone around a blasthole. International Journal of Rock Mechanics and Mining Sciences, 40, pp. 485-495.

GHEIBIE, S. et al. (2009) Modified Kuz-Ram fragmentation model and its use at the Sungun Copper Mine. International Journal of Rock Mechanics and Mining Sciences, 46, pp. 967-973.

GOODARZI, M., MOHAMMADI, S. and JAFARI, A. (2015) Numerical analysis of rock fracturing by gas pressure using the extended finite element method. Petroleum Science, 12, pp. 304-315.

HU, R. et al. (2015) Numerical study on crack propagation by using softening model under blasting. Advances in Materials Science and Engineering.

HUSTRULID, W. and LU, W. (2002) Some general design concepts regarding the control of blast-induced damage during rock slope excavation. In: Proc. 7th Rock Fragmentation by Blasting. 
KWON, S. et al. (2009). An investigation of the excavation damaged zone at the KAERI underground research tunnel. Tunnelling and underground space technology, 24, pp. 113.

MAVKO, G., MUKERJI, T. and DVORKIN, J. (2009) The rock physics handbook: Tools for seismic analysis of porous media. Cambridge university press.

OLSSON, M. and BERGQVIST, I. (1996) Crack lengths from explosives in multiple hole blasting. In: Proceedings of the Fifth International Symposium on Rock Fragmentation by Blasting, Fragblast-5, Montreal, Quebec, Canada, pp. 187-91. Monteral.

OUCHTERLONY, F. (1997) Prediction of crack lengths in rock after cautious blasting with zero inter-hole delay. In: Fragblast, 1, pp. 417-444.

OUCHTERLONY, F. (2005) The Swebrec@ function: linking fragmentation by blasting and crushing. Mining Technology, 114, pp. 29-44.

OUCHTERLONY, F., OLSSON, M. and BERGQVIST, I. (2002) Towards new Swedish recommendations for cautious perimeter blasting. In: Fragblast, 6, pp. 235-261.

SAHARAN, M. R. and MITRI, H. S. (2008) Numerical procedure for dynamic simulation of discrete fractures due to blasting. Rock mechanics and rock engineering, 41, pp. 641-670.

TORBICA, S. and LAPCEVIC, V. (2014) Rock breakage by explosives. European International Journal of Science and Technology, 3, pp. 96-104.

TORBICA, S. and LAPČEVIĆ, V. (2015) Estimating extent and properties of blastdamaged zone around underground excavations. Rem: Revista Escola de Minas, 68, pp. 441-453.

WHITTAKER, B. N., SINGH, R. N. and SUN, G. (1992) Rock fracture mechanics: principles, design, and applications. Elsevier.

YI, C., SJÖBERG, J. and JOHANSSON, D. (2017) Numerical modelling for blastinduced fragmentation in sublevel caving mines. Tunnelling and Underground Space Technology, 68, pp. 167-173.

ZHU, Z., MOHANTY, B. and XIE, H. (2007) Numerical investigation of blastinginduced crack initiation and propagation in rocks. International Journal of Rock Mechanics and Mining Sciences, 44, pp. 412-424. 